\title{
EDITORIAL
}

\section{EMPODERAMIENTO ECONÓMICO DE LAS MUJERES. NADIE SE QUEDA ATRÁS. ACCIONES PROCURANDO EL CAMBIO}

Nadie se Queda Atrás, Acciones Procurando el Cambio ${ }^{1}$ centra el empoderamiento económico de las mujeres como el corazón de la Agenda 2030. Sólo si las mujeres participan en todas las esferas de la vida, incluyendo la económica, se alcanzarán los Objetivos del Desarrollo Sostenible (oDs). Este documento trabajado a lo largo de seis meses incluye recomendaciones para lograr el cambio mediante acciones concretas entre gobiernos, sector privado y sociedad civil. El Estado deberá transmitir cambios y mejoras en las políticas públicas, en las leyes del sistema jurídico, ampliar el gasto público para lograr más empleos, mejorar la estrecha relación entre las diferentes asociaciones e intentar aumentar la representación de las mujeres en la vida pública.

¿Cómo transformar las condiciones macroeconómicas en un país? Si se invirtiera el $2 \%$ del pIB en la economía del cuidado se podría incrementar la tasa de empleo entre 4 y $7 \%$, se crearían entre 59 y $70 \%$ de nuevos empleos. La economía del cuidado es la base para que las mujeres puedan insertarse a la esfera económica y accedan a la educación, vivienda digna y empleo con salario justo.

A partir de las decisiones macroeconómicas y de políticas sectoriales, como han sido los presupuestos con enfoque de género, las condiciones de la otra mitad de la población podrán alcanzar los oDs. Las mujeres no son una población homogénea, es muy importante la diferenciación que existe entre mujer rural y urbana, así como la mujer en la economía formal e informal. Este documento tiene recomendaciones para terminar y erradicar normas culturales patriarcales, violencia de género, invisibilidad pública y lograr derechos humanos en la esfera económica.

Eliminar la inequidad de género para el año 2030 es el reto a alcanzar. Es un imperativo conocer las barreras estructurales que impiden el empoderamiento económico y la inclusión de las mujeres en las actividades económicas. Se han logrado determinar siete ejes conductores tomando en

1 "Leave No One Behind. Taking Action for Transformational Change on Women's Economic Empowerment", reporte entregado por el Alto Panel para el Empoderamiento Económico de las Mujeres al Secretario de Naciones Unidas, marzo 2017. Este documento es continuación de "Leave No One Behind. A Call for Gender Equality and Women's Economic Empowerment" aprobado en la Asamblea General de Naciones Unidas, septiembre 2016. 
cuenta a las mujeres en la economía formal, en la economía informal, tanto en el ámbito rural, así como dirigiendo empresas. Dichos ejes comprenden los siguientes enunciados: 1) Combatir las normas adversas y promover los modelos positivos; 2) Asegurar la protección jurídica y reformar las leyes y regulaciones discriminatorias; 3) Reconocer, reducir y redistribuir el trabajo y cuidado no remunerados; 4) Generar activos -Digitales, financieros de propiedad; 5) Cambiar la cultura y las prácticas empresariales; 6) Mejorar las prácticas del sector público en el empleo y las compras públicas, y 7) Fortalecer la visibilidad, la voz colectiva y la representación.

La mayor parte las mujeres necesitan incluir sus voces, cambiar las normas y buscar ser reconocidas como agentes económicos para lograr una mayor visibilidad, dada su importancia en el crecimiento y desarrollo de la sociedad. La acción y el liderazgo para todas las mujeres es prioritario para una sociedad que necesita desenvolverse en un ambiente de austeridad, proteccionismo y homofobia. No importa la clase social, la raza y si son legales o ilegales independiente del país donde estén ubicadas. Por lo tanto, las organizaciones son determinantes en la eliminación de la inequidad por género. Ser conscientes a través del sector público, sector privado, la sociedad civil y las empresas se hace necesario para lograr la inclusión de las mujeres en la toma del liderazgo y facilitarles, de esta manera, mejores oportunidades.

En la producción y circulación, las mujeres participan ya sea desde el campo, la economía informal o formal. Hay cinco preguntas que cada organización deberá plantearse si realmente todos están por el empoderamiento económico de las mujeres. Las preguntas son en primera instancia si: ¿es el mismo pago para todas las mujeres y hombres en todos los niveles?; ¡está balanceada la fuerza de trabajo entre hombres y mujeres, incluyendo a los trabajadores en casa?; ¡cuánto se gasta en empresas propiedad de mujeres?; ¡tiene la organización programas para mujeres?; ¿ se han aplicado iniciativas con perspectiva de género? Estos cuestionamientos son importantes.

Las mujeres representan más de la mitad de la población en escala mundial y participan en todas las actividades económicas, políticas y sociales. El hecho de que las teorías económicas neoclásica y heterodoxa, e incluso la teoría del desarrollo, no incluyan el trabajo del cuidado de las mujeres en las cuentas nacionales, debido a que no existe una relación de intercambio monetario, constituye un eje prioritario de análisis si realmente se pretende un desarrollo equitativo y de calidad en el futuro.

Un aspecto fundamental que debe cambiar desde la ciencia económica es el reconocimiento de la economía del cuidado, que por razones culturales y por la división del trabajo no está contabilizada. El trabajo del cuidado no 
es remunerado, pero constituye el pilar de la sociedad y más allá de la reproducción de la fuerza de trabajo, las mujeres transmiten los valores culturales de un país. Razón por la cual, para impulsar la Agenda del Desarrollo 2030 es muy importante aprobar políticas públicas que respondan a los siete ejes planteados en el documento "No dejar a nadie atrás. Un llamado a la acción sobre la igualdad de género y el empoderamiento económico de las mujeres".

En el presente número de Problemas del Desarrollo, el artículo "Hacia una economía política de la competencia. La empresa transnacional”, de Raúl Ornelas, realiza un análisis sobre los paradigmas de la teoría de la empresa. Destaca dos teorías esenciales para el estudio de la competencia: la de los costos de transacción y la de las cadenas de valor. Las teorías que se ubican dentro de la primera línea priorizan el ambiente institucional. A partir de una expansión, la presencia de las empresas legitima la estrecha relación con el Estado que no interviene en la economía para dejar el crecimiento de las empresas a través de la internalización de los costos de transacción e insertar los espacios nacionales en circuitos globales de la producción.

El paradigma de las cadenas de valor nos centra en una red interorganizacional donde mediante una mercancía básica o producto se relacionan todos los actores económicos en la elaboración de la mercancía final. El autor pone a debate cómo la presencia de las empresas y sus cadenas de producción sujetan el éxito económico y la supervivencia de regiones y naciones: su aportación es centrarse en el poder desde la interpretación de Gramsci.

Luis Fernando García y Moritz Cruz explican en el artículo "Desempleo en América Latina: ¿flexibilidad laboral o acumulación de capital?” si el desempleo en América Latina se debió a la flexibilidad laboral o a la acumulación de capital. Al plantear la visión teórica neoclásica y post-keynesiana los autores llegan a la conclusión de que la primera es la que da el marco teórico para explicar la caída del desempleo. Si bien, la flexibilización y las reformas laborales fueron importantes, la inversión pública fue un disparador del empleo. Por lo cual, fomentar una política de inversión pública articulada a una política industrial es prioritario para los Estados, con el objeto de presentar alternativas a la tendencia del ciclo económico y mantener el empleo y destinarlo hacia la producción de bienes con alto valor agregado.

El artículo "Recesiones de México en los albores del siglo xxı", de Pablo Mejía, Miguel A. Díaz y Reyna Vergara, profundiza en las recesiones de los años 2001-2003 y 2008-2009. Durante las últimas cuatro décadas las recesiones han sido una constante en México, pero el análisis de las señaladas en el artículo difieren de las anteriores porque se originaron en Estados Unidos. Después de hacer un análisis de las causas y de las políticas implementadas por 
los bancos centrales, se observan los efectos de la Gran Recesión en México a través de acciones basadas en una política fiscal de carácter contra-cíclico. El aumento del gasto público mediante programas de infraestructura y apoyo a empresas y familias, provocó la disminución de los ingresos tributarios y el financiamiento se realizó con deuda pública. A pesar de los esfuerzos del gobierno, la última recesión mostró la fragilidad de la economía resultado de la intrínseca relación con la economía de Estados Unidos.

"Financiarización y sector carretero en México", de José Enrique Mendoza pone en juego la participación de las Asociaciones Público Privadas (APP) y la construcción de infraestructura pública a través de concesiones en actividades tradicionalmente realizadas por la banca de desarrollo. Los gobiernos al promover la utilización de las APP para la construcción de carreteras, aeropuertos, sector energético, incluso obras de infraestructura, parten de la falta de recursos del Estado. El proceso de financiarización de los bienes públicos no es una nueva modalidad, sino que responde a la bursatilización de activos públicos y es un mecanismo de financiamiento que se implementó en Inglaterra, y otros países desarrollados hace más de tres décadas, pero ha venido para quedarse en la generación de infraestructura de México y otros naciones latinoamericanas. La rentabilidad de las obras es pagada por la sociedad a largo plazo a las empresas que participan en la construcción de las obras y, por el otro lado, el gobierno adquiere deudas que responden a los intereses de los inversionistas en los mercados financieros.

Una de las aportaciones del artículo escrito por Gabriel Oyhantçabal y Martín Sanguinetti, "El agro en Uruguay: renta del suelo, ingreso laboral y ganancias", radica en profundizar respecto a la renta del suelo y el papel de los dueños de la tierra. Propietarios y asalariados mantienen relaciones de ingresos asimétricas. Por su parte, el Estado participa a través de las retenciones en mayores ingresos del boom de las ganancias agrícolas. El análisis de la distribución social del ingreso realizada desde los años de crisis hasta el boom de los commodities en Uruguay y el agotamiento del ciclo de los commodities arroja resultados interesantes.

El artículo "Renta extractiva y la minería del cobre en el Perú", cuyo autor es Yuri Landa, plantea una pregunta clave para los países latinoamericanos que se vieron beneficiados por el boom de los commodities. La pregunta plantea si los montos de dinero recibidos por los gobiernos ¿sirvieron para sentar las bases de un crecimiento económico o desarrollo económico para el futuro? El autor, al centrarse sobre el tema del cobre y la minería en el Perú, realiza un análisis del impacto en la infraestructura tanto a nivel distrital y departamental. Muestra en las conclusiones que la extracción del cobre tuvo 
un efecto directo, positivo en la infraestructura educativa, salud sanitaria y vial, dependiendo de las diferentes regiones a pesar de un Estado con una escasa visión de sostenibilidad y una regionalización en formación.

Liu Xuedong en su artículo "Desincorporación del suelo colectivo y el sistema urbano en China 1990-2015" analiza el crecimiento de las zonas urbanas en diferentes ciudades del país asiático. El proyecto de urbanización involucra varios actores entre ellos las diferentes propiedades y usos del suelo rural y urbano que son incompatibles. La aceleración de la urbanización y la expropiación del suelo de propiedad colectiva profundizan enfrentamientos al interior de las comunidades. Señala que la urbanización es un proceso indispensable para la modernización de una economía. Al trasladar a zonas urbanas o convertir zonas rurales en áreas de mayor productividad, donde los factores productivos tradicionales son eliminados por áreas de mayor concentración industrial, China se enfrenta al sistema de tenencia dual.

Alicia Girón

La Dirección de la Revista Ciudad Universitaria, marzo 2017 